Original Research

\title{
Efficiency of Nutrient Removal from Household Wastewater in Nonwoven Bioreactors
}

\author{
Krzysztof Chmielowski ${ }^{1}$, Robert Mazur ${ }^{2}$, Agata Nowak ${ }^{3}$, \\ Dawid Bedla ${ }^{4}$, Jakub Mazurkiewicz ${ }^{5}$, Marcin Spychała ${ }^{6}$ \\ ${ }^{1}$ Department of Sanitary Engineering and Water Management, University of Agriculture in Kraków, Poland \\ ${ }^{2}$ Department of Geoinformation Photogrammetry and Remote Sensing of Environment, \\ AGH University of Science and Technology in Kraków, Poland \\ ${ }^{3}$ Department of Environmental Management and Protection, \\ AGH University of Science and Technology in Kraków, Poland \\ ${ }^{4}$ Department of Ecology, Climatology and Air Protection, University of Agriculture in Kraków, Poland \\ ${ }_{5}^{5}$ Institute of Biosystems Engineering, Poznan University of Life Sciences, Poznań, Poland \\ ${ }^{6}$ Department of Hydraulic and Sanitary Engineering Poznan University of Life Sciences, Poznań, Poland
}

Received: 30 January 2018

Accepted: 27 April 2018

\begin{abstract}
Our paper presents results of nutrient removal from household wastewater in the bioreactors with nonwoven filters. The experimental system was constructed from two groups of bioreactors in laboratory scale with gravity-fed wastewater supply. The variable differentiating the work of both tested systems was the method of sewage dosing. In both experimental groups, there was a statistically significant reduction ratio of nitrite nitrogen, ammonia nitrogen, phosphate, and sulfide ions. In spite of the marked difference between concentrations of investigated nutrients in treated wastewater between the experimental groups was not possible to demonstrate in most cases the statistically significant differences. The bioreactors fed once every 12 hours showed an additional effect of desiccation of part of a nonwoven filter and a significant deterioration in the quality of treated sewage. The tested systems of reactors provide the scientific promises for their use on an industrial scale as a system with partial treatment of household sewage. The contents of nutrients in treated wastewater, however, still exceeds the permissible level specified in the standard for treated sewage.
\end{abstract}

Keywords: wastewater treatment, nonwoven filters, biofilm, biological wastewater treatment

\section{Introduction}

Nutrient removal is a very important criterion in household sewage treatment systems. The process of sewage treatment must ensure an adequate degree of nutrient reduction from raw sewage, both in municipal treatment plants and in small treatment plants, below $50 \mathrm{PE}$ [1]. The use of membrane bioreactors (MBR) in the treatment of wastewater is limited to small objects with relatively small organic pollutant load.

*e-mail: mazurrob@gmail.com 


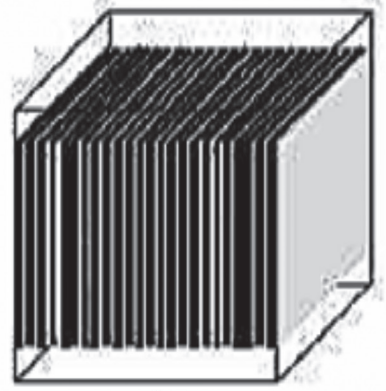

a)

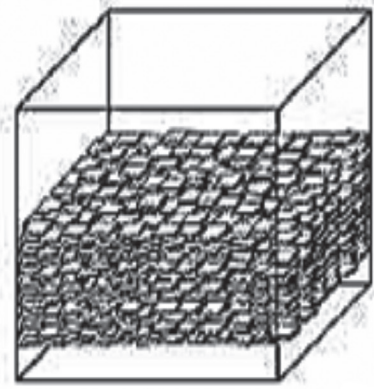

b)

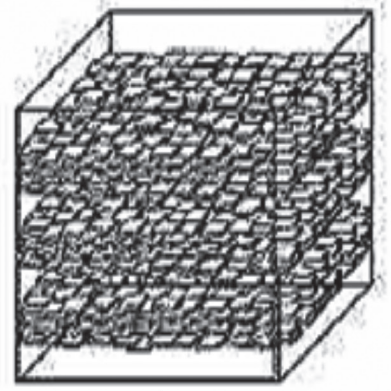

c)

Fig. 1. Different types of nonwoven bed reactor constructions [7]: a) hanging, b) sandwich-layer, and c) three separate layers.

Synthetic nonwovens can be used in filter bed bioreactors, where they participate in both mechanical and biological sewage treatment. Filtration allows separation of mineral particles larger than nonwoven pores, while its biological clogging (as a result of biological membrane growth) ensures proper $\mathrm{BOD}_{5}$ reduction [2]. The process of clogging lump formation strictly affects flow reduction through the filter, but also improves the clarification of the effluent [3]. Due to the preferential properties of synthetic nonwovens as carriers for biological membrane biomass, they are more commonly used in hybrid purification plants rather than as independent treatment systems [4]. The process of nutrient removal in this type of MBR reactor is significantly less understood than the process of organic substances reduction, and strictly depends on the specificity of the nonwoven filter construction. Different types of MBR bioreactors will be characterized by varying efficiencies of nutrient removal. Aerobic conditions play a major role in the nitrification and denitrification processes and have a direct impact on the level of reduction or increase in nutrient concentration in treated sewage [5]. Guo et al. [6] presented the results of their investigations of fluidized bed biofilter employing nonwoven bedding material. They obtained in the research a significant $\mathrm{BOD}_{5}$ along with nutrient reduction.

Other types of suspended sprinkled non-woven beds are still a novelty on the market of wastewater treatment and studies on their construction and appropriate dosage of wastewater onto the surface of the bed are still ongoing [8]. The nonwoven components used in the MBR bioreactors are economically most reasonable, therefore they are an alternative to MBBR and SBR treatment plants, even with often less efficient sewage treatment [9].

Due to the variety of properties and conditions (nonwoven thickness and type, supply regime, type of wastewater) there is a very wide range of potential research directions for nonwoven filters technology. Similar to what is described in this paper, types of filters have already been investigated; however, those studies were carried out under other conditions for other thicknesses and other constructions [10-13]. Nonwoven filters can potentially be useful in practice as a device for septic tank effluent treatment, and significantly reduce the risk of clogging. Clogging is one of the main problems occurring in the case of wastewater discharging to the ground, as was evidenced by numerous publications on this subject [14]. There are also studies indicating the significant effect of this type of filter on the removal of fibrous particles from wastewater. These particles are also indicated as one of the significant causes of clogging [15]. Moreover, nonwoven filters can remove dissolved organic compounds with relatively high efficiency [16]. Likewise, it is worth noting that organic compounds are a significant part of septic tank effluent content [17].

\section{Materials and Methods}

In this paper, the authors present the results of studies on nutrient removal from household sewage in two groups of experimental nonwoven filters fed gravitationally. The first group of reactors, R1-R3 (Fig. 2a), was fed quasi-continuously (once per hour), and almost complete submergence of the reservoir with wastewater was maintained. The R4-R6 filter system (Fig. 2a) was fed once every 12 hours in order to expose both sides of the nonwoven fabric and to improve the oxygen balance of the biological membrane.

The development of biological membrane (biofilm) was the first stage of research - i.e., the stage of bed startup. It is a key element in wastewater treatment in the applied technology. The kinetics of development and functioning of the membrane and its metabolism are closely dependent on oxygen conditions and substrate load [18]. Models of transport and substrate concentration changes in the steady-state biological membrane are shown in the zero-, first-, and secondorder differential equations [18]. The excessive membrane growth and increase in thickness after exceeding critical values $(2-3 \mathrm{~mm})$ result in decreased efficiency of treatment, due to the deterioration of conditions of substrate diffusion to the inner membrane parts [19]. After reaching the stage of mature biofilm form (Fig. 3) (with the abundance of EPS), the nonwoven bed was considered to have started up, and 
a)

b)

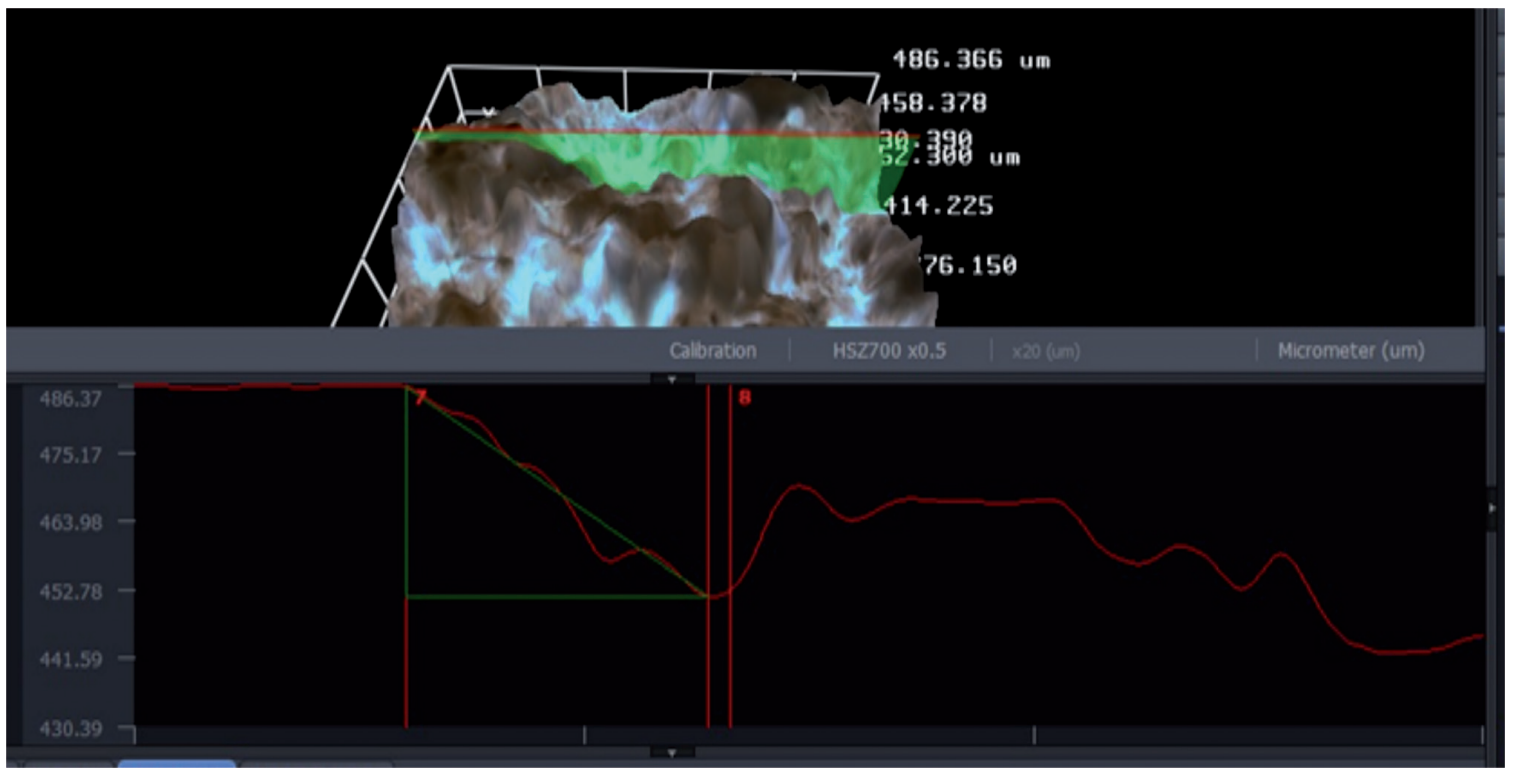

Fig. 2 Construction of nonwoven bioreactor systems: a) Bioreactors R1-R3 b) Bioreactors R4-R6).

household sewage treatment efficiency tests began. After this stage, the natural process is peeling off the excess membrane fragments and their deposition on the reactor bottom, hence the reactors had to be cleaned from the secondary sludge in order to prevent organic matter purification.
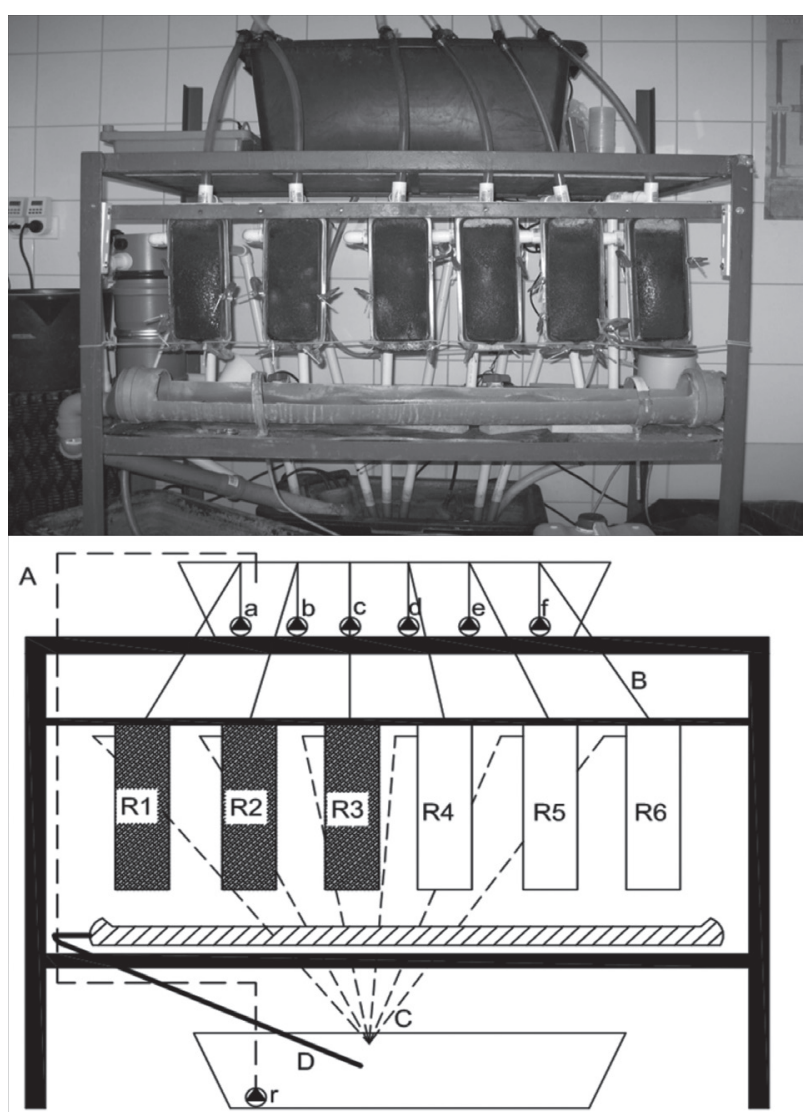

Fig. 3. Morphology of biofilm growing on the nonwoven filter after startup period of beds.
The aim of the conducted study was to determine the effect of aerobic conditions on the nutrient removal efficiency in treated sewage in nonwoven bioreactors, and to assess the efficiency of nutrient removal in treated sewage in the started-up nonwoven filter.

\section{Characteristics of the Experimental System}

In the first reactor system, R1-R3, the dosing took place once per hour for 20 seconds. The very slow retention of sewage through the nonwoven fabric provided almost complete submergence of the reservoirs throughout the study period. In the R4-R6 group, the effluent dosage took place every 12 hours (also for 20 seconds) in order to expose the nonwoven fabric and to improve the aerobic conditions for treatment. The capacity of each bioreactor was $\mathrm{V}=1.5 \mathrm{dm}^{3}$, while the surface of the nonwoven filter in plan $\mathrm{A}=189 \mathrm{~cm}^{2}$. In each filter, at least one surface of the nonwoven fabric was exposed (outer side), which allowed the membrane to actively transport oxygen for aerobic microorganisms. Polyfelt TS 20 nonwoven fabric filter was used for the experiment.

Each bioreactor had a nonwoven filter made of two Polyfelt TS 20 geotextile layers, surface attached on metal cubes, adapted for the needs of the nonwoven bioreactor. The effluent was dosed under hydrostatic pressure and then passed through the nonwoven filter. Each nonwoven fabric on one (inner) side had contact with raw sewage and on the other (outer) - with atmospheric air. The wastewater was both mechanically filtered and purified by the biological membrane on the nonwoven fabric.

Anoxic conditions prevailed in all reactors. The R4-R6 group of filters, as a result of a long period of the membrane exposure, showed a negative effect of the upper part over-drying and mechanical 
perforation of the nonwoven fabric, which negatively affected the wastewater treatment process in this layer. The measurements were performed using treated sewage from the bottom part of the nonwoven fabric in the group, which was not subjected to over-drying.

\section{Conducted Measurements}

Sewage for the study originated from a detached house and was collected after the septic tank in the period from December 2012 to June 2013. For all types of sewage (raw and treated) the nutrient levels were determined and basic physicochemical parameters were measured:

- Total nitrogen - Kjeldahl method with sample mineralization, ammonia nitrogen, nitrite and nitrate nitrogen, as well as phosphates by a colorimetric method on Spectroquant NOVA 60 spectrometer.

- Physicochemical parameters $\mathrm{pH}, \mathrm{O} 2$, red-ox.

The following equipment was used for the above-described measurements: Spectroquant NOVA 60 (Merck) spectrometer, FOSS Tecator Kjeltec nitrogen mineralizer and distiller, $\mathrm{CP}-315 \mathrm{pH}-$ meter and a CX401 (Elmetron) multifunction device. The results between the groups were compared with the t-Student test in Statistica.

\section{Results}

\section{Changes in the Sewage Flow through Filters}

The analyses were conducted for 9 groups for ammonia nitrogen and 4 for Kjeldahl nitrogen in measurement sessions during full catalysis of the biological membrane in the nonwoven filter of the bioreactors (Table 1). Both the mechanical and biological clogging process of the nonwoven filter reduced the sewage flow through the nonwoven fabric surface. Throughout the study period, the flows remained at $0.1-0.02 \mathrm{dm}^{3} \cdot \mathrm{h}^{-1}$, which ensured the adequate contact of wastewater with the biological membrane. For both groups, R1-R3 as well as R4-R6, treated sewage from the properly functioning membrane was tested, therefore in both cases the retention level was similar.

\section{Changes in the Concentration of Ammonia and Kjeldahl Nitrogen}

In most experimental groups the results indicate the reduction of ammonia and Kjeldahl nitrogen as compared to raw sewage. Significantly better results were obtained for the group of reactors with full submergence of the nonwoven fabric from the inside (Figs 4 and 5) (Table 1). Despite the apparent

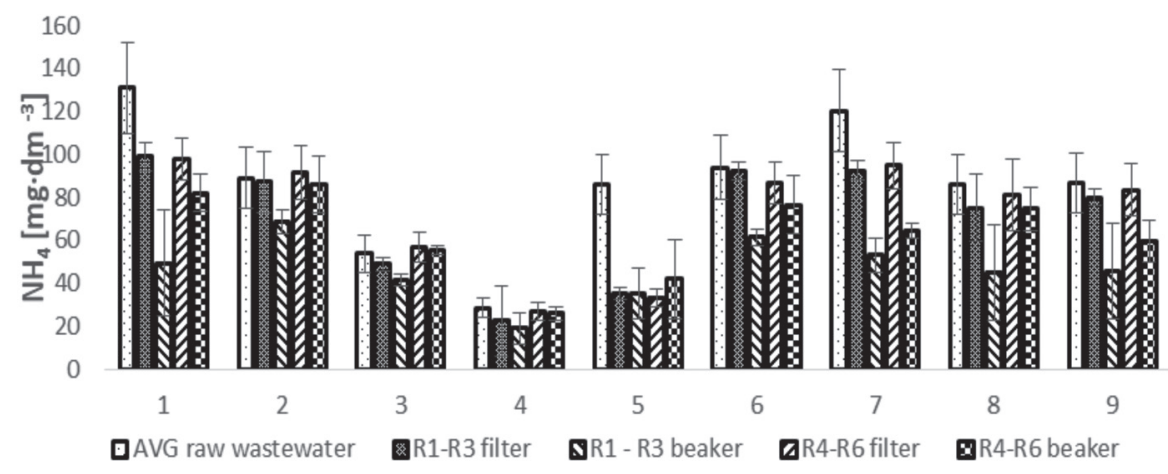

Fig. 4. Changes in mean concentrations of ammonia nitrogen ions in raw wastewater, in filters, and after treatment for both experimental groups (R1-R3 and R4-R6).

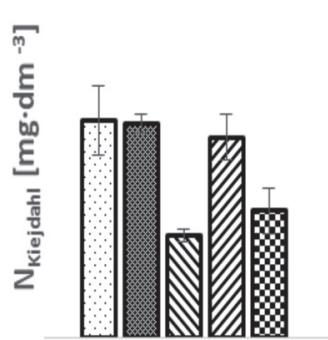

1

aAVG raw wastewater

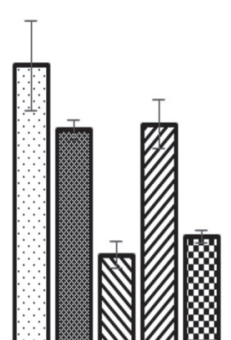

2

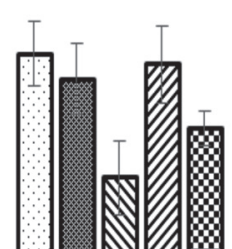

3

घR4-R6 filter

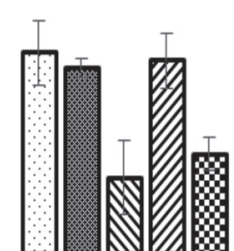

4

Fig. 5. Changes in mean concentrations of Kjeldahl nitrogen in raw wastewater, in filters, and after treatment for both experimental groups (R1-R3 and R4-R6). 


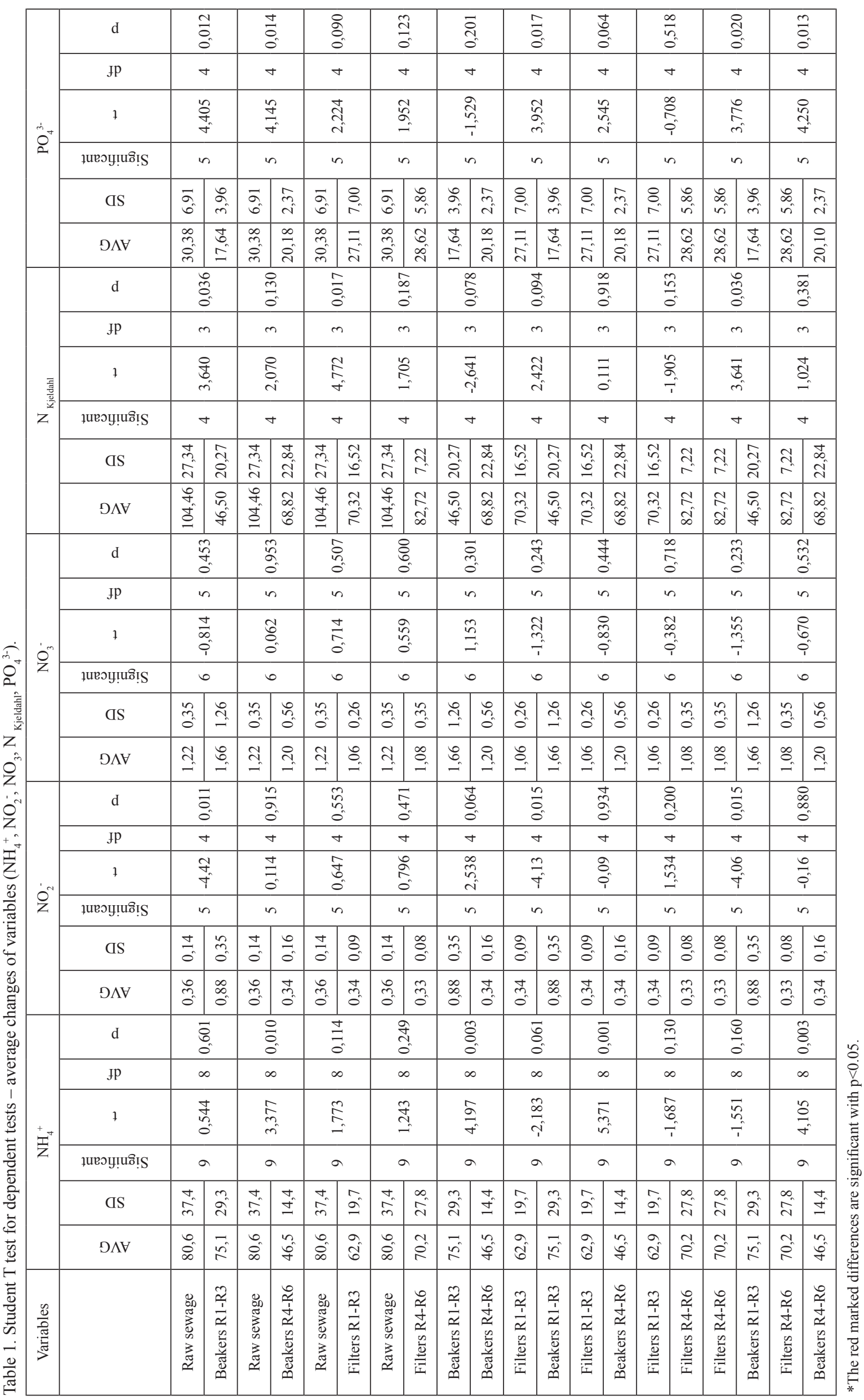



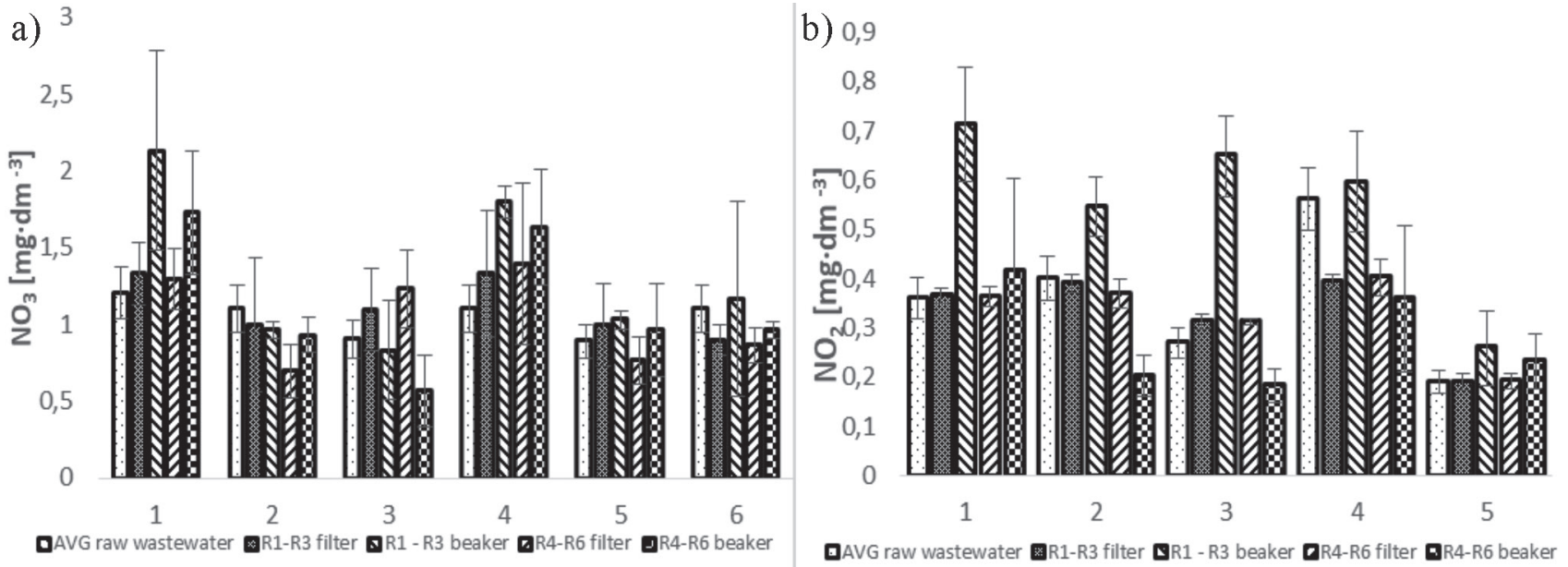

Fig. 6. a) Changes in mean concentrations of nitrate (V); and b) nitrate (III) ions in raw wastewater, in filters, and after treatment for both experimental groups (R1-R3 and R4-R6).

tendency for nitrification in the R1-R6 system in most measurements it is impossible to unanimously conclude based on the conducted study whether the process is stable enough to assure the proper reduction degree of ammonia nitrogen.

\section{Changes in the Concentration of Nitrate (III) and Nitrate (V) Ions}

Figs $6 a$ ) and b) show the changes in the concentrations of (III) and (V) nitrate ions, which indicate the course of the nitrification process. In both the group of reactors with full submergence and with periodic dosage every 12 hours, the differences between sewage in the bioreactor and treated sewage can be observed.

However, statistical analyses do not clearly indicate whether the differences between the concentrations of both ions in treated wastewater for both experimental groups are significant or not (Table 1). Only some measurement sessions show such differences, while in the others the differences are not statistically significant (Table 1).

\section{Changes in Phosphate (V) Concentrations}

Phosphate concentrations during the study period were characterized by high variability.

Fig. 7 shows the differences in phosphate (V) concentrations between sewage treated and supplied to the filters. The reduction in the concentrations of the tested ions between raw and treated sewage was observed in each measurement session. These differences are statistically significant; therefore the reduction level for both systems was determined and the two experimental groups were compared (Fig. 7, Table 1). The efficiency of phosphate reduction on R1-R3 filters was from $15.4 \%$ to $58.3 \%$, while for R4-R6 filters it was within the range $14.7-44.6 \%$ (Fig. 7). a)

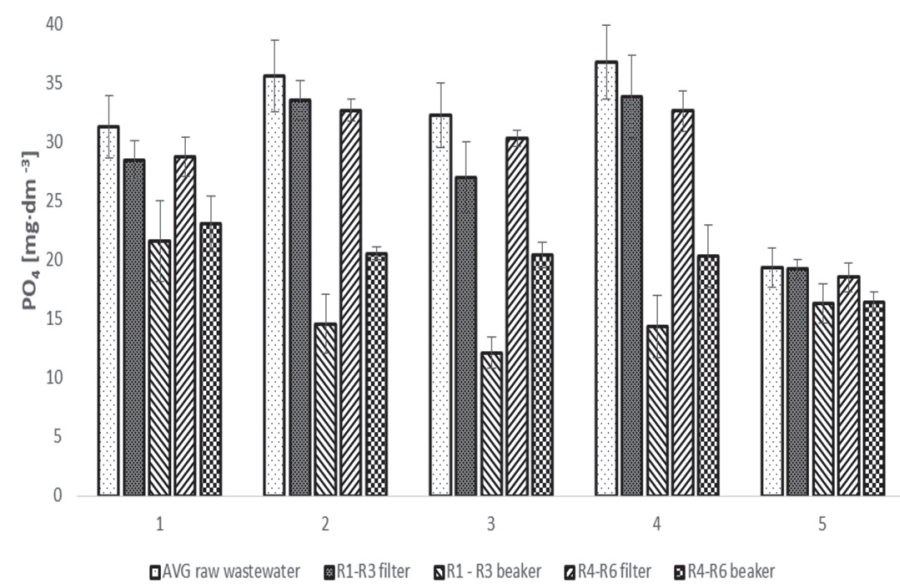

b)

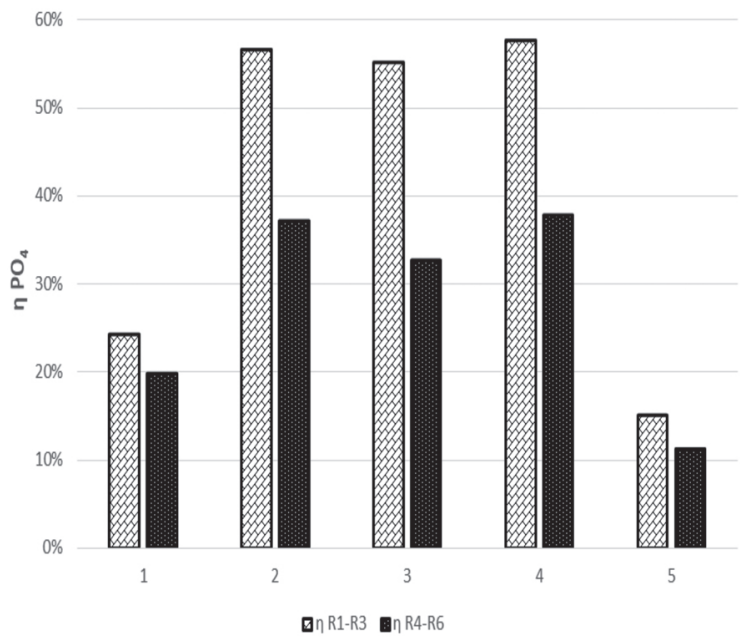

Fig. 7. a) Changes in mean concentrations of orthophosphate ions in raw wastewater, in filters, and after treatment for both experimental groups (R1-R3 and R4-R6) and, b) the efficiency of reduction of orthophosphate ions in wastewater fed to the filters and treated on nonwoven fabric. 

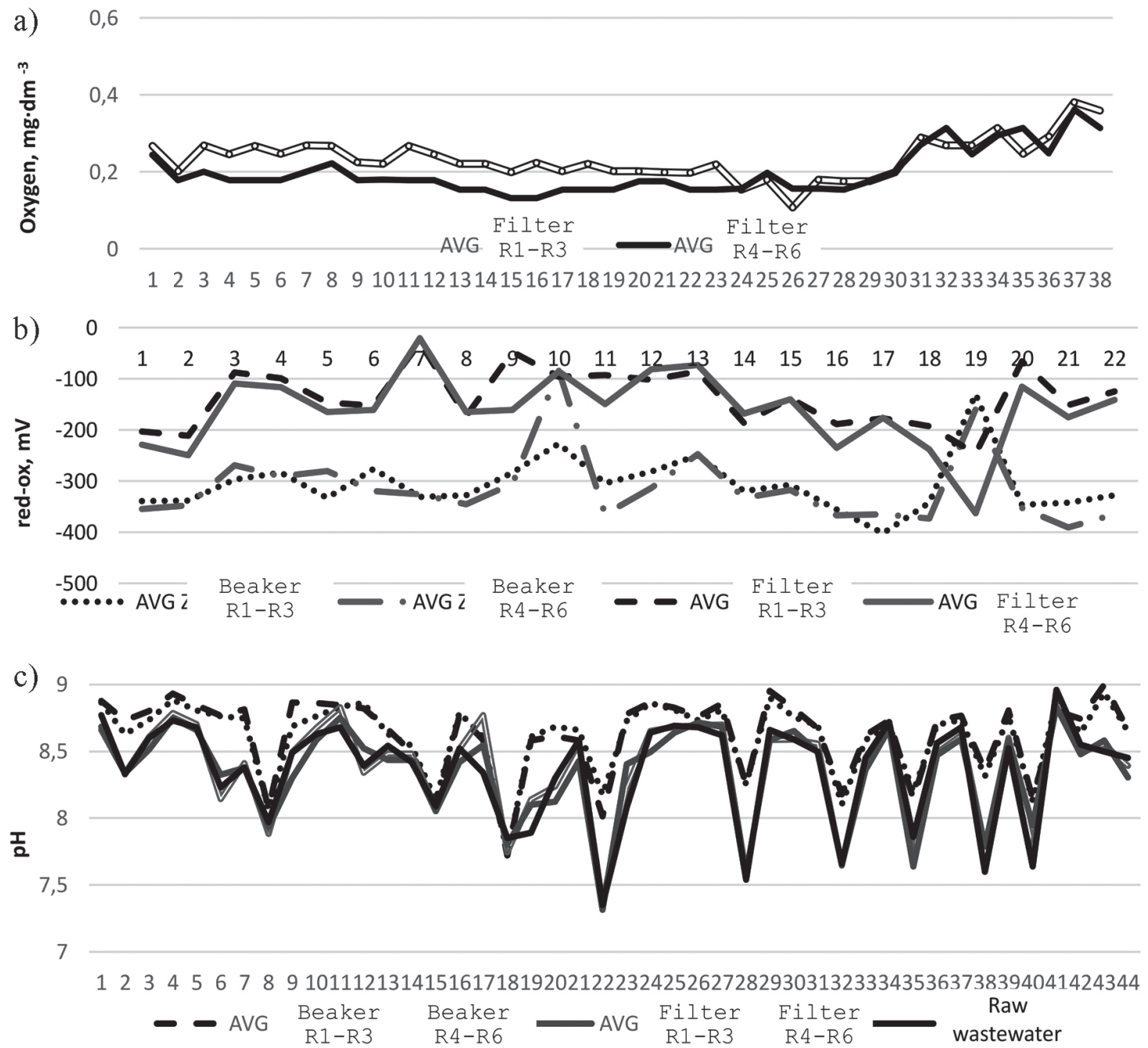

Fig. 8. Changes in values of: A) dissolved oxygen, B) red-ox, and C) $\mathrm{pH}$ in raw wastewater, in filters, and after treatment for all experimental groups (R1-R3 and R4-R6).

\section{Mean Changes in $\mathrm{pH}$ at the Inflow and Outflow} from Nonwoven Filters

The changes of $\mathrm{pH}$ in dosed sewage and treated sewage for both groups are presented in the graph (Fig. 8). Statistical tests with Student's t-test confirmed that $\mathrm{pH}$ differences between dosed and treated wastewater are statistically significant (Table 2). Changes in red-ox values indicate the treatment process and are characteristic of the process of organic compounds reduction in biological oxidation (Fig. 8b, Table 2). In both experimental groups, the concentration of dissolved oxygen indicated anoxic conditions inside bioreactors and ranged from 0.11 to $0.38 \mathrm{mg} \cdot \mathrm{dm}^{-3}$ (Fig. 8a).

\section{Mean Changes in Nutrient Level at the Inflow and Outflow from Nonwoven Filters}

Analyses of the nutrient removal efficiency in household sewage were carried out simultaneously with the reduction of organic substances in the same test cycle. A significant level of $\mathrm{COD}$ and $\mathrm{BOD}_{5}$ removal was demonstrated, and results of these studies have also been published [20]. In the case of nutrients, the removal of most nitrogen and phosphorus forms from sewage became efficient after the startup period of the biological membrane (as a result of biological clogging). The decrease in flows significantly improved the efficiency of wastewater treatment by extending the substrate's contact with the biological membrane [1]. The anaerobic conditions in the filter caused high levels of ammonia nitrogen to be maintained; nevertheless, its reduction in the nonwoven bed is noticeable (Fig. 4). The beneficial effect was also observed in the reduction of Kjeldahl nitrogen concentration, as its level in treated sewage is higher than the ammonia nitrogen reduction rate, which may indicate an intense reduction of organic nitrogen in the biological oxidation process [2] (Fig. 5, Table 1). Due to the zonal oxygen availability, i.e., only in the outer part of the nonwoven fabric, the nitrification conditions are favorable in the limited range only. An increase in the concentration of nitrate ions and reduction of nitrate (III) ions can be observed in treated sewage. Their mutual relationship may result 
Table 2. Student T-test for dependent tests - average changes of variables ( $\mathrm{pH}$, red-ox, conductivity).

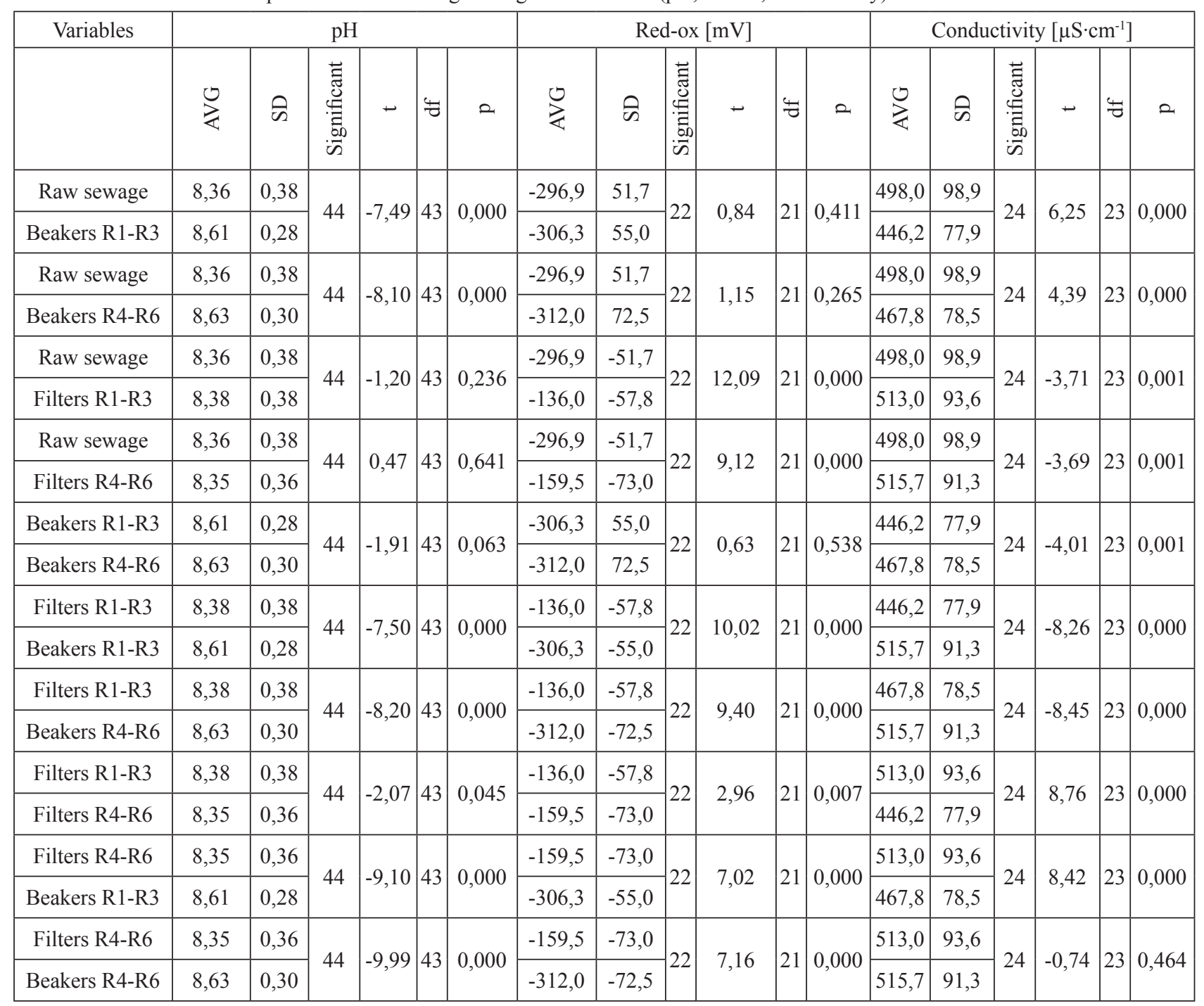

*The red marked differences are significant with $\mathrm{p}<0,05$.

from the kinetics of transformations in the nitrification zone (Fig. 6). Anaerobic conditions in bioreactors may favor denitrification if nitrate and nitrite ion diffusion rates also occur in this direction. This would promote the removal of nitrogen from sewage and explain the reduction of ammonia nitrogen levels by nitrification and denitrification [21]. The growth of biological membrane also favors the assimilation of a part of nitrogen forms into biological structures of the biofilm [21-23]. The phosphorus reduction rate was variable and ranged in all reactors from $11 \%$ even up to $57 \%$ (Fig. 7b). A decrease in phosphate (V) ion concentrations was observed in all experimental groups (Fig. 7a). In all experimental groups, the effect of nitrogen and phosphorus removal in treated sewage on the nonwoven filter (with started-up biological membrane - Fig. 2) was obtained. Due to the specificity of the nonwoven bioreactors' construction, also the literature reports provide very variable levels of nutrient reduction in treatment plants with the nonwoven fabric as a carrier for biological membrane [11, 24]. Significant differences in red-ox values were also observed between treated and dosed sewage, indicating the oxidation and reduction processes in the treatment process (Fig. 8, Table 2). Also, the changes in $\mathrm{pH}$ indicate the positive effect of sewage treatment in this type of reactor (Fig. 8).

Unfortunately, with the non-woven filter scheme used, the quality of treated sewage with respect to the analyzed nutrients still did not meet the requirements specified in the standard for treated wastewater [25, 26]. When considering the studies on vertical flow sand filters [27], hybrid systems could be developed that would combine them with the solution presented in this study. The investigated systems may be used in the phased additional sewage treatment. It is proposed to use such systems for the treatment or additional treatment of sewage with relatively low loads of beds with organic pollutants expressed in the values of COD and $\mathrm{BOD}_{5}$. 


\section{Conclusions}

1. The investigated systems of nonwoven bioreactors together with the household sewage supply method showed a positive effect of nutrient removal from raw sewage on the nonwoven fabric.

2. Further research on the improvement of this type of system should be carried out in order to achieve a full reduction rate of nutrients to the level specified in the standard for treated sewage.

3. The studies showed that at the current operating level of bioreactors, they can be successfully used as cleaning modules in hybrid systems with a flow rate of up to $5 \mathrm{~m}^{3} \cdot \mathrm{d}^{-1}$.

4. Filters of this type are not recommended for use in the treatment of sewage with high nitrogen and phosphorus loads.

5. Despite anaerobic conditions in bioreactors, nitrification processes take place on the surface of the nonwoven fabric filters, ensuring nutrient removal.

\section{Acknowledgements}

Paper has been prepared within the scope of the AGH UST statutory research no. 11.11.150.949. and Research conducted under the framework of DS3347/KISiGW/2017 were financed from grants for science granted by the Ministry of Science and Higher Education.

\section{References}

1. SPYCHAŁA M., ŁUCYK P. Effect of the thickness of textile filter on organic compounds and nutrients removal efficiency at changeable wastewater surface level. Science, Nature, Technologies/Nauka, Przyroda, Technologie. 9 (3), 2015.

2. KOMESLI O.T., MUZ M., AK M.S., BAKÝRDERE S., GÖKÇAY C.F. Comparison of EDCs removal in full and pilot-scale membrane bioreactor plants: effect of flux rate on EDCs removal in short SRT. Journal of environmental management. 203, 847, 2017.

3. REN X., SHON H.K, JANG N., LEE Y., LEE J., CHO K., KIM I. Novel membrane bioreactor (MBR) coupled with a nonwoven fabric filter for household wastewater treatment. Water Research. 44 (3), 751, 2010.

4. EYVAZ M., ARSLAN S., GÜRBULAK E., YÜKSEL E. Textile Materials in Liquid Filtration Practices. Current Status and Perspectives in Water and Wastewater Treatment. In Textiles for Advanced Applications. InTech. 11, 293, 2017.

5. KONIECZNY K. Effectiveness of wastewater treatment with the use of the biological membrane reactors. Annual Set - The Environment Protection. 17, 1034, 2015.

6. GUO W.S., XING W., NGO H.H., HU A.Y.J., PALMER C.G., ZHANG R. Enhancement of Organics Removal by an Integrated Nonwoven Media Biofilter - submerged Membrane Adsorption Hybrid System. Applied Membrane Science \& Technology. 9, 1, 2017.
7. SIEGRIST R.L. Treatment Using Porous Media Biofilters. In Decentralized Water Reclamation Engineering. Springer, Cham. 365, 2017.

8. CHONG M.N., HO A.N., GARDNER T., SHARMA A.K., HOOD B. Assessing decentralized wastewater treatment technologies. Correlating technology selection to system robustness, energy consumption, and GHG emission. Journal of Water and Climate Change. 4 (4), 338, 2013.

9. XIAO K., XU, Y., LIANG S., LEI, T., SUN J., WEN $X$., HUANG X. Engineering application of membrane bioreactor for wastewater treatment in China: current state and future prospect. Frontiers of Environmental Science \& Engineering. 8 (6), 805, 2014.

10. SPYCHAŁA M., BŁAŻEJEWSKI R., NAWROT T. Performance of innovative textile biofilters for domestic wastewater treatment, Environmental Technology. 34 (2), 157, 2013.

11. SPYCHAŁA M., STARZYK J. Bacteria in non-woven textile filters for domestic wastewater treatment, Environmental Technology. 36 (8), 937, 2015.

12. SPYCHAŁA M., SOWIŃSKA A., STARZYK J., MASŁOWSKI A. Protozoa and metazoa relations to technological conditions of non-woven textile filters, Environmental Technology. 36 (15), 1865, 2015.

13. SPYCHAŁA M., NAWROT T., PAWLAK M. Capacity of textile filters for wastewater treatment at changeable wastewater level - a hydraulic model. Acta Scientiarum Polonorum Formatio Circumiectus. 15 (4), 421, 2016.

14. NIEĆ J., SPYCHAŁA M. Hydraulic Conductivity Estimation Test Impact on Long-Term Acceptance Rate and Soil Absorption System Design, Water. 6, 2808, 2014.

15. SPYCHAŁA M., NIEĆ J., PAWLAK M. Preliminary study on filamentous particle distribution in septic tank effluent and their impact on filter cake development, Environmental Technology. 34 (20), 2829, 2013.

16. SPYCHAŁA M. Skuteczność filtrów włókninowych do oczyszczania ścieków ze stałym poziomem piętrzenia, Acta Scientiarum Polonorum Formatio Circumiectus. 15 (1), 19, 2016.

17. MAKOWSKA M., SPYCHAŁA M. Organic compounds fractionation for domestic wastewater treatment modeling, Polish Journal of Environmental Studies. 23 (1), 131, 2014.

18. KORKUT E.N, MARTIN J.P., YAMAN C. Wastewater treatment with biomass attached to porous geotextile baffles. Journal Environ. Engineering. 132 (2), 284, 2006.

19. GŁAZ B.E. The influence of oxygen conditions on the wastewater treatment efficiency by using nonwoven fabric filter. Master thesis UP-Poznań, Department of Hydraulic and Sanitary Engineering. 2013.

20. MAZUR R., BEDLA D., CHMIELOWSKI K., NOWAK A., MAZURKIEWICZ J. Wpływ warunków tlenowych na skuteczność oczyszczania ścieków bytowych w technologii zatapialnych filtrów włókninowych. Przemysł Chemiczny. 95 (8), 1513, 2016.

21. MAO N. Engineering design of high-performance filter fabrics. In Engineering of High-Performance Textiles. 435, 2018.

22. GHANIMEH S., KHALIL C. A., MOSLEH C. B., HABCHI C. Optimized anaerobic-aerobic sequential system for the treatment of food waste and wastewater. Waste Management. 71, 767, 2018.

23. XU M., CAO J., LI C., TU Y., WU H., LIU W. Operational and biological analyses of branched water-adjustment 
and combined treatment of wastewater from a chemical industrial park. Environmental technology. 39 (2), 253, 2018.

24. Regulation of the Minister of the Environment on the conditions to be met for the introduction of sewage into waters or soil and on substances particularly harmful to the aquatic environment. Journal of Laws of the Republic of Poland (Dz. U. 2014 poz. 1800). 2014.

25. PARCO V., DU TOIT G. J.G., EKAMA G.A. The Impact of High Mixed Liquor Concentration (3-13 gVSS/ $/$ ) on the Kinetic Rates of the N and P Removal Bioprocesses in Membrane Biological Nutrient Removal Activated
Sludge Systems. In Frontiers International Conference on Wastewater Treatment and Modelling. Springer, Cham. 3, 2017.

26. ZHANG Q., YU C., FANG J., XU, H., JIANG Q., YANG S., WANG W. Using the Combined Fenton-MBR Process to Treat Cutting Fluid Wastewater. Polish Journal of Environmental Studies. 26 (3), 1375, 2017.

27. CHANG M.C, TZOU, W.Y, CHUANG S.H., CHANG W.K. Application of non-woven fabric material in membrane bioreactor processes for industrial wastewater treatment. In $5^{\text {th }}$ international membrane science and technology conference, Sydney. 10, 2003. 